Ankara Ecz. Fak. Mec.

12. 83 (1982)
J. Fac. Pharm Ankara

12. 83 (1982)

\title{
Türkiye'de Yetişen Fumaria L. Türleri ve Bu Türlerin Alkaloitleri Üzerinde Araştırmalar*
}

I. Türkiye Fumaria"larının Morfolojik Özelikleri.

Turkish Species of Fumaria L. and Their Alkaloids

I. Morphological Characters of Turkish Species of

\section{Fumaria}

Bilge ŞENER* *

\section{GİRIŞ}

Fumaria L. cinsi, Papaveraceae familyasının "Fumarioideae" alt familyasına ait bir genustur. Yeryüzünde monografi $(1,2)$ ve floralarda $(3,4,5,6,7,8)$ kayitlı 46 kadar tür ile temsil edilen Fumarialar, kuzey yarıkürenin Amerika dışındaki 1lıman ve subtropikal iklim bölgelerinde yetişmektedir. Memleketimizde doğal olarak 13 Fumaria L. türü (3) yetişmektedir. Bu türlerden yaygın olarak bulunan $F$. officinalis L., halk arasında "Şahtere, sedefotu" gibi isimlerle bilinmekte ve bu bitkinin topraküstü kısımları kurutulduktan sonra, çay gibi kaynatılarak, egzama ve sedef hastalı̆̆ına karşı kullanılmaktadır.

Fumaria ismi, Latince "fumus terrae" deyiminden gelmektedir. Grimsi-yeşil renkte olan Fumaria türlerinin, topraktan çıkan bir duman görünümünde olmasından dolayı, bitkiye bu isim verilmiştir. Ayrıca, özsuyunun gözleri duman gibi yaşarttı̆̆ 1 da bilinmektedir $(9,10)$.

Redaksiyona verildiği tarih: 18 Eylül $\mathbf{1 9 8 2 .}$

* Aynı isimli Doçentlik Tezinin bir bölümüdür. Sınav tarihi: Ekim 1981.

** Farmakognozi Birimi, Eczacılık Fakültesi, Ankara Üniversitesi. 
Offisinal tür olarak kabul edilen $F$. officinalis'in topraküstü kısımları, ilk çağlarda tonik, depüratif ve vermifüj etkilerinden (9) dolayı kullanılmıştır. Daha sonraları safra salgısı üzerine de etkili olduğu anlaşılmış ve bitkiden karaciğer hastalıklarının tedavisinde yararlanılmıştır $(11,12)$. Bunlardan başka $F$. officinalis ekstrelerinin, düz kaslar üzerinde spazmolitik bir etkisinin bulunduğu da bilinmektedir (13). F. officinalis yerine, $F$. capreolata L. ve $F$. vaillantii Lois.'den hazırlanan preparatlar da kullanılmıştır $(14,15)$.

Bitkide, etken madde olarak başlica alkaloitler bulunmaktadir. Ayrıca az miktarda tanen (10), şekerler (10), organik asitler (10, 16) ve fenolik maddelerin (17) yanında, bitkinin tohumlarında sabit yă ve sterollerin $(18,19)$ varlı̆̆ 1 da bilinmektedir.

Fizyolojik etki ve kimyasal yapı bakımından çeşitli alkaloitleri içeren Fumaria cinsinin ülkemizde yetişen 13 türünün alkaloitleri üzerinde bugüne kadar herhangi bir araştırma yapılmamıştır. $\mathrm{Bu}$ nedenle memleketimizde yetişen Fumaria türlerinin alkaloitleri üzerinde bir çalışma planlanmış ve çalışma amacı;

- Türlerdeki alkaloitlerin yapılarının ve miktarlarının tayini,

- Önceden incelenmiş olup, memleketimizde de yetişen türlerin alkaloitlerinin birbiri ile karşılaştırılması,

- Bu türlerin, fizyolojik etkisi bilinen alkaloitler için bir kaynak olup olmayacağının saptanması ve

- Türler arasında, alkaloit gruplarına göre bir sınıflandırmanın yapılıp yapılamayacă̆ının ortaya konulması şeklinde belirlenmiştir.

Kimyasal çalışmalara geçilmeden önce, toplanan türlerin morfolojik özelikleri tayin edilerek, kolaylıkla tanınmalarında yararlanılabilecek karakterler saptanmıştır.

\section{MATERYAL}

Ülkemizin hemen her bölgesinde, deniz seviyesinden $2000 \mathrm{~m}$ yüksekliklere kadar, tarla içleri, yol kenarları, tepe yamaçlarıve çit aralarında rastlanabilen Fumariaları, kurak ve nemli topraklarda yetişebilen türleri bulunmaktadır. Bu türler arasında, tırmanıcı özelik gösterenler de vardir. 
Yeryüzünde 46 türü bulunan bu cinsin memleketimizde 13 türü yetişmektedir. Avrupa falorasında (8), 13 türe ilâve olarak, Trakya'da bir başka türün daha bulunduğu kayıtlı ise de, henüz bu türe rastlanılmamıştır.

Örneklerin toplandıkları yöreler*:

1. F. gaillardotii Boiss.

C5 HATAY: Antakya, $150 \mathrm{~m}, 27.4 .1957$, Davis, Hedge. 27264! Seint-Pierre kilisesi civarındaki kayalık yerler, $150 \mathrm{~m}, 26.4 .1978$, Şener (AEF 6725)!

2. F. macrocarpa Parlatore

B I İ Z M İ R: Bornova, $300 \mathrm{~m}, 10.5 .1976$, Seçmen (EGE 178)! İzmir-Çeşme arası, Çeşme'ye $10 \mathrm{~km}$, çitler arasında, $30 \mathrm{~m}, 18.5 .1978$, N. Tanker ve ark. (AEF 7116)! Çeşme, Ovacık köyü, Akarca mevkii, $125 \mathrm{~m}$, 19.5.1978, N. Tanker ve ark. (AEF 7117)!

C1 MUĞLA: Marmaris-Datça yolu, böğürtlen çitleri, $100 \mathrm{~m}$, 7.5.1978, Şener (AEF 6723)!

3. F. capreolata L.

C3 Antalya: Antalya, Aspendos, 50 m, 6.4.1956, Davis, Polunin, 25657!

Antalya, Perge, $40 \mathrm{~m}, 20.4 .1975$, Koyuncu, Coşkun (AEF 5146)!

C5 HATAY: Harbiye, şelâle civarı, 180 m, 25.4.1978, Şener ve ark. (AEF 6722)!

Seint-Pierre kilisesi, kayalıklar, $150 \mathrm{~m}, 26.4 .1978$, Şener (AEF 7118)!

4. F. judaica Boiss.

B 1 İ Z M İ R: Çeşme-Çiftlik arası, $110 \mathrm{~m}, 17.5 .1978$, N. Tanker ve ark. (AEF 7115)!

C1 M U Ğ LA: Marmaris, 24.4. 1976, Başaran (AEF 5251)!

* ISTE'de bulunan Fumaria L. örnekleri, Prof. Asuman Baytop tarafından İstanbul Ecz. Fak. Mec, 13, 23-25 (1977) de yayınlanmıştır. 
Marmaris-Datça yolu, bögürtlen çitleri, $100 \mathrm{~m}$, 7.5.1978, Şener (AEF 6724)!

Datça, Çiftlik yarımadası, 10.2.1980 N. Tanker (AEF 7041)!

F. cilicica Hausskn.

A4 ANKARA: Kizilcahamam-Kargasekmez, $1400 \mathrm{~m}, \quad 26.5$. 1970, Güngör ( H U B 9 10 )!

A9 ARTVİN: Kordevan dağı, $200 \mathrm{~m}, 28.6 .1957$, Davis, Hedge, 30183 !

B3 AFYON: Bayat, Otlugedik sırt1, $1450 \mathrm{~m}, 27.6 .1975$, Vural (ANK 324)!

B4 ANKARA: Kayaş, $650 \mathrm{~m}, 21.5 .1978$, Şener ve ark. (AEF 6716)!

C3 IS PARTA: Sütçüler, $1000 \mathrm{~m}, 16.4 .1975$, Peşmen, Güner (HUB 2031)!

C5 HATAY: Seint-Pierre kilisesinin civarındaki tarlalar, $150 \mathrm{~m}$, 26.4.1978, Şener (AEF 7137)!

C6 SEYHAN: Adana, Osmaniye, $500 \mathrm{~m}, 17.4 .1957$, Davis, Hedge, 26716 !

Haruniye'ye $3 \mathrm{~km}$, tarlalar, 380 m., 27.4.1978, Şener (AEF 7138)!

C7 URFA: Siverek, $1250 \mathrm{~m}, 19.5 .1957$, Davis, Hedge, 28307!

C8 DİYARBAKIR：Diyarbakır， $650 \mathrm{~m} ， 31.5 .1957$, Davis, Hedge, 28789!

C8 MARDİN : Ömerli, $1000 \mathrm{~m}, 20.5 .1978$, Zel (AND 1139)!

F. densiflora DC. Sin: F. micrantha Lag.

Al E Dİ R E: Edirne-Havsa aras1, 180 m., 30.6.1978, Şener (AEF 7127)!

A2 BURSA: Gemlik, Armutlu-Şahintepe, Mermeră̆a mevkii, $780 \mathrm{~m}, 26.6 .1978$, Şener (AEF 6718)!

B1 İZM İ R: İzmir-Urla arası, Urla'ya $1 \mathrm{~km}$, yol kenarları, $30 \mathrm{~m}$, 17.5.1978, N. Tanker ve ark. (AEF 7126)! 
C5 İ ÇEL: Tarsus, 20 m, 8.4.1957, Davis, Hedge, 26509! F. officinalis L.

Al ÇANAKKALE: Çanakkale-Nara arası, tarlalar, $350 \mathrm{~m}$, 28.6.1978, Şener (AEF 7135)!

A2 BURSA: Gemlik, Armutlu-Şahintepe, Mermeră̆a mevkii, $780 \mathrm{~m}, 26.6 .1978$, Şener (AEF 6717)!

B 1 İ Z M İ R: Çeşme-Çiftlik arası, $110 \mathrm{~m}, 17.5 .1978$, N. Tanker ve ark. (AEF 7131)!

B3 KONYA: Beyşehir, Aşım durağı, 1150 m, 23.5.1969, Karamanoğlu ve ark. (AEF 1813)!

B4 ANKARA: Lalahan, tarlalar, $1000 \mathrm{~m}, 15.7 .1977$, Şener ve ark. (AEF 5997)!

Beypazar1, İnözü mevkii, $1600 \mathrm{~m}, 21.5 .1978$, Şener (AEF 7132)!

Çubuk barajı, $975 \mathrm{~m}, 28.5 .1978$, Şener (AEF $7133)$ !

Keçiören, 2.6.1933, Krause (ANK 4264)!

C1 MUĞLA: Marmaris, tarla kenarları, $40 \mathrm{~m}, \quad 7.5 .1978$, Şener (AEF 7130)!

C3 ANTAlYA: Antalya, $1120 \mathrm{~m}, 13.5 .1956$, Birand (ANK 11)! Kemer, Faselis koyu, $100 \mathrm{~m}, 21.3 .1979$, Peşmen ( HUB 4173)!

C3 ISPARTA： Sütçüler, $1100 \mathrm{~m}, 27.4 .1974$, Peşmen (HUB $1216)$ !

G5 HATAY: Harbiye, bahçe kenarları, $100 \mathrm{~m}$, 25.4.1978, Şener (AEF 7129)!

F. petteri Reichb. subsp. thuretii (Boiss.) Pugsley Sin: F. thuretii Boiss., F. pikermiana Boiss.

A2 BURSA: Gemlik, Armutlu-Şahintepe, Mermeră̆a mevkii, tarla kenarlar1 $780 \mathrm{~m}, 26.6 .1978$, Şener (AEF 6720)!

C2 MUĞLA: Kale, tepeler, $1095 \mathrm{~m}, 8.5 .1978$, Şener (AEF $6721)$ ! 
C4 İ ÇE L: Gülnar-Gilindere, 700 m, 15.4.1956, Davis, Polunin 26021 !

9. F. kralikii Jordan Sin: F. anatolica Boiss.

Al E D İR N E: Edirne-Lalapaşa yolu, $240 \mathrm{~m}, 30.6 .1978$, Şener (AEF 7125)!

B 1 İZ M İR: İzmir-Çcşme arası, yolun iki tarafındaki tarlalar, $30 \mathrm{~m}, 17.5 .1978$, N. Tanker ve ark. (AEF 6719)! B4 ANKARA: Beynam orman1, $1400 \mathrm{~m}, 20.5 .1978$, Şener (AEF 7122)!

Ayaşbeli, $1200 \mathrm{~m}, 21.5 .1978$, Şener (AEF 7123)!

Kizilcahamam Kargasekmez, 1100 m, 24.6. 1978, Şener, (AEF 7124)!

Hasanoğlan köyü, 10.5.1960, Çetik (ANK 285)!

C3 IS PARTA： Eğridir, Kovada gölü, 27.6.1971, Pamukçuoğlu ( H U B 1470)!

Süçüler, $1080 \mathrm{~m}, \quad 26.5 .1974$, Peşmen, Güner ( H UB 1553)!

C6 SEYHAN: Haruniye, $700 \mathrm{~m}, 18.4 .1957)$, Davis, Hedge, (26809)!

K. MARAŞ: Göksun, 1200 m., 15.5.1978, Yıldız (HUB $1817)$ !

10. F. parviflora Lam.

Al ÇANAKKALE: Çanakkale-Nara arası, $350 \mathrm{~m}, 28.6 .1978$, Şener (AEF 7149)!

Al TEKİR D A Ğ : Tekirdağ-Marmara Ereğlisi'ne $5 \mathrm{~km}, 200$ $m, 29.6 .1978$, Şener (AEF 7150)!

B 1 İ Z M İ R: İzmir - Urla kavşağ 1,30 m. 17.5.1978, N. Tanker ve ark. (AEF 6712)!

B4 ANKARA: Kepekli boğazı, $850 \mathrm{~m}, 20.5 .1978$, Şener (AEF 7147)!

Çubuk barajı, $975 \mathrm{~m}, 28.5 .1978$, Şener (AEF $7148)$ ! 
B 7 E R Z İ N C A N : Bağıştaş, $870 \mathrm{~m}, \quad 17.5 .1980, \quad$ Yıldırımlı ( HUB 2766)!

B 9 B İTLİS: Tatvan, $700 \mathrm{~m}, 4.6 .1972$, Peşmen (H U B 2802)!

C3 İ PART A： Eğridir, $1000 \mathrm{~m}, 6.5 .1972$, Koyuncu (AEF $1935)$ !

C4 İÇEL: Anamur, 5 m, 14.4.1956, Davis, Polunin, 25945!

C5 HATAY: Harbiye, tepeler, $200 \mathrm{~m}, 25.4 .1978$, Şener (AEF 7145)!

Seint-Pierre kilisesi civarındaki kayalık yerler; 150 m, 26.4.1978, Şener (AEF 7146)!

C6 GAZİANTEP: Gaziantep, $900 \mathrm{~m}, \quad 11.5 .1957$, Davis, Hedge, 27824 !

11. F. microcarpa Boiss. ex Hausskn.

A8 RİZE: Çamlıhemşin, Hisarcık köyü, 1800 m, 30.8.1980, Güner ( H U B 2775)!

A9 KARS : Kars-Susuz, $1800 \mathrm{~m}, 15.6 .1957$, Davis, Hedge, 29585 !

Kars-Sarıkamış arası, $2200 \mathrm{~m}, 24.6 .1973$, Karamano ğlu ve ark. (AEF 4198)!

B7 E RZ İ NCAN : Şelale çevresi, 1300 m, 22.6.1973, Koyuncu (AEF 3913)!

İliç-Bağıştaş arası, $100 \mathrm{~m}, 27.4 .1980$, Yıldırımlı ( H UB 2686)!

B8 ERZ U R M : Tortum çağlayanı civarı, $1600 \mathrm{~m}, 15.7 .1977$, Şener (AEF 7139)!

89 VAN: Gevaş-Edremit arası, $1690 \mathrm{~m}, 6.6 .1978$, N. Tanker ve ark. (AEF 6715)!

12. F. vaillantii Lois. Sin: F. schrammii (Hausskn.) Velenovsky B 1 İ Z M İ R: Bornova, tarlalar, 4.1932, Schwarz (ANK 24)!

B3 E S KİŞEHİR： Eskişehir-Türkmen dağ1，1200m，9.7.1977, Ekim (ANK 2551)! 
B4 ANKARA: Beynam ormanı, $1000 \mathrm{~m}, 6.6 .1969$, İnceoğlu (ANK 17898)! $6265)$ !

Kirıkkale, $1200 \mathrm{~m}, 4.6 .1977$, M. Tanker (AEF

Lalahan, $1000 \mathrm{~m}, 15.7 .1977$, Şener ve ark. (AEF 5996)!

Beypazar1, 1600 m, 21.5.1978, Şener (AEF 7143)!

B6 MALATYA: Doğanşehir, $1200 \mathrm{~m}, 10.5 .1957$, Davis, Hedge 27726 !

B8 ERZURUM : Pasinler-Horasan, 1650 m, 12.6.1957,

Davis, Hedge 2937)!

B9 VAN: Van kalesi civarındaki tarlalar, $1560 \mathrm{~m}, 6.6 .1978$, N. Tanker ve ark. (AEF 6713)!

C3 ANTALYA: Elmalı, Çı̆̆lıkara, Avlan beli, 1490 m, 25.6. 1975, Çetik (ANK 1669)!

C3 IS PARTA： Eğridir, Melikler, $1100 \mathrm{~m}, 30.6 .1974$, Peșmen ( HUB 1453)!

C5 KONYA: Aydos dağ1, 1100 m, 26.6.1976, Erik (HUB 1532)!

F. asepala Boiss.

B3 AFYON: Bayat, Otlugedik sirt1, $1450 \mathrm{~m}, 27.6 .1975$, Vural (ANK 323)!

B4 ANKARA: Beytepe, 1000 m, 13.5.1975, Erik (HUB 1942)!

Nallihan, Uluhan, $1400 \mathrm{~m}, 17.7 .1978$, Akman (ANK 9749)!

Sivrihisar, tarla kenarlar1, $980 \mathrm{~m}, \quad 2.6 .1978$, Şener (AEF 7153)!

B7 E R Z İ N C A N : Kurutiket civar1, $900 \mathrm{~m}, 10.6 .1940$, Băğda (ANK 46)!

B 8 E R Z U U M : Pasinler-Horasan, $1650 \mathrm{~m}, 12.6 .1957$, Davis, 29408 !

B9 B İT Lİ : Tatvan, $1700 \mathrm{~m}, 30.6 .1954$, Davis, 23381!

Tatvan, bahçe kenarları, $1800 \mathrm{~m}, \quad 6.6 .1978$, N. Tankerve ark. (AEF 6711)! 
Tatvan, Akdamar kilisesi civar1, $1610 \mathrm{~m}, 6.6 .1978$, N. Tanker ve ark. (AEF 7155)!

C1 MUĞLA: Marmaris, tarla kenarları, $40 \mathrm{~m}, \quad 7.5 .1978$, Şener. (AEF 7134)!

C3 ANTALYA: Elmalı çevresi, $1800 \mathrm{~m}, \quad 30.6 .1974$, Çetik (ANK, 1668)!

Kemer, Tahtalı dağ 1600 m., 4.5.1979, Peşmen ( HUB 4608)!

IS PARTA： Ĕgridir, Yaka köyü, $1700 \mathrm{~m}, \quad$ 1.7.1974, Peşmen ( H U B 1553)!

C6 K. MARAŞ: Ahır dağ $1,1300 \mathrm{~m}, 2.5 .1957$, Davis, Hedge. 27375 !

C7 URFA: Hilvan, $600 \mathrm{~m}, 18.5 .1957$, Davis, Hedge, 26466! Akçakale, Harran, $550 \mathrm{~m}, 17.4 .1980$, Güner ( H U B 2249)!

C8 DİYARB AKIR： Ergani, $750 \mathrm{~m}, 1.6 .1957$, Davis, Hedge, 29548 !

C 10 H A KKARİ: Yüksekova, $1800 \mathrm{~m}, \quad 19.6 .1975$, Güner ( H UB 1345)!

Fumaria türlerinin ülkemizdeki yayılışı, aşağıda verilen haritada toplu bir şekilde görülmektedir. Haritanın hazırlanmasında Flora of Turkey and the East Aegean Islands (3) da belirtilen ve AEF (Ankara Üniversitesi Eczacilık Fakültesi), ANK (Ankara Üniversitesi Fen Fakültesi), EGE (Ege Üniversitesi Fen Fakültesi), HU B (Hacettepe Üniversitesi Botanik Bölümü) İSTE (İstanbul Üniversitesi Eczacılık Fakültesi) herbaryumlarında bulunan örneklerden yararlanılmıştır.

Bugüne kadar herbaryum örneği alınmamış olan C1 karesinden $F$. asepala ve $F$. maerocarpa, B1'den $F$. densiflora, B4'den $F$. kralikii, B9'dan ise $F$. vaillantii bu araştırma sırasında toplanmıştır. 


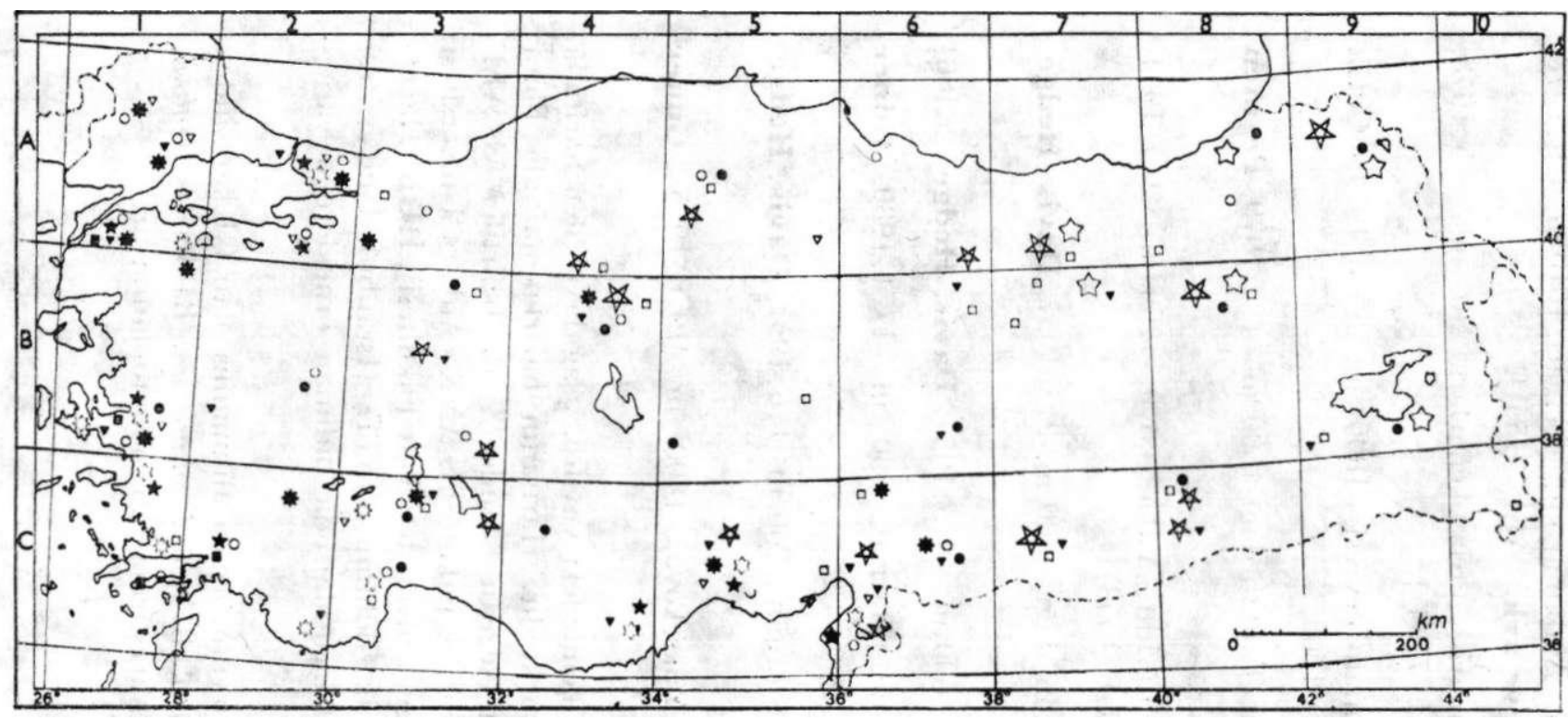

FUMARIA L. Türlerinin Türkiye'deki Yayılıșı.

1. F. officinalis

- F. densiflora

हु F. cilicica

罡 F. kralikii
F. gaillardotii

\&

$\Delta \quad$ F. capreolata

0

F. judaica $\checkmark$ F. parviflora

口 F. vaillantii

\&5. microcarpa

- F. asepala

A F. petteri subsp. 
Fumaria L. cinsi, bitkinin tek yıllık, yapraklarının pinnatisekt ve meyvanın bir tohumlu nuks tipinde oluşu ile, Fumarioideae alt familyasının diğer genusu olan Corydalis Medik. (Çok yıllık, yapraklar ternat, meyva çok tohumlu kapsül)'lerden kolayca ayrılır (3).

Memleketimizin hemen her bölgesinde yetişebilen Fumaria cinsinin yurdumuzda bulunan 13 türü için aşă̆ıdaki morfolojik özelikler saptanmıştır*.

Fumaria türleri, 15-150 cm yüksekliğinde, tüysüz, dik, yayılmış veya tırmanic1 bitkilerdir.

Yapraklar 5-7 cm boyunda, petiol ince uzun, hemen hemen lamina kadar; lamina bi-tripinnatisekt, lobları linear (a), linearlanseolat (b), lancelat (c) ya da oblong-lanseolat (d).

Çiçek durumu sık ya da gevşek rasemus olup, yaprakların karş1sında bulunur. înfloresans kisa $(1-1.5 \mathrm{~cm}), 10-16$ çiçekli ve sık (a), 6-12 çiçekli ve gevşek (b) ya da uzun (4-6 cm), 23-35 çiçekli ve sık (c), 14-22 çiçekli ve gevşek (d).

Brakteler pedisele eşit uzunlukta, linear (a) veya oblong (b); pediselden kısa, linear-lanseolat (c) ya da pediselden uzun, linearoblong (d).

Çiçekler zigomorf olup, 4-14mm kadar büyüklüktedir.

Kaliks petaloid, beyaz, iki sepalli, korisepal, düşücü; korollamn $1 / 2$ - $1 / 10 \mathrm{u}$ kadar uzunluktadır, bazan da körelmiştir. Sepal-

* Verilen sayısal değerler, her türden 10 örnek ölçülmesi sonucu, ortalama hesaplama ile bulunmuştur. 


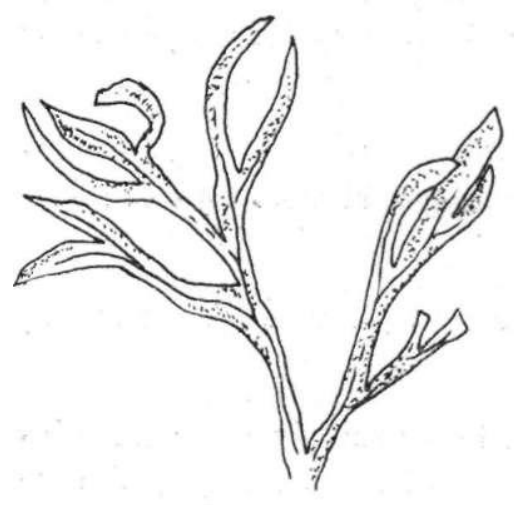

a parviflora* * microcarpa

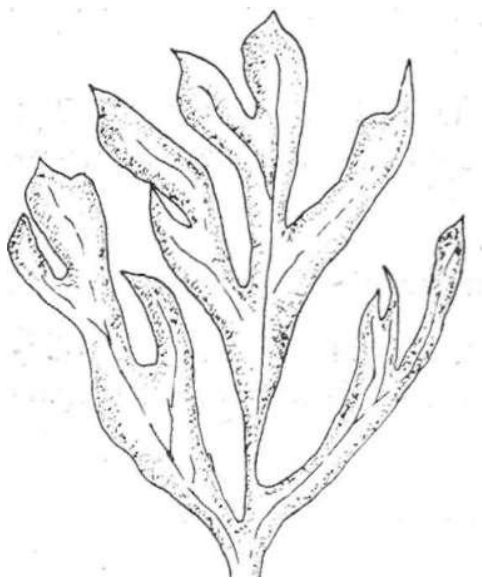

c

cilicica kralikii, officinalis densiflora, petteri subsp. thuretii

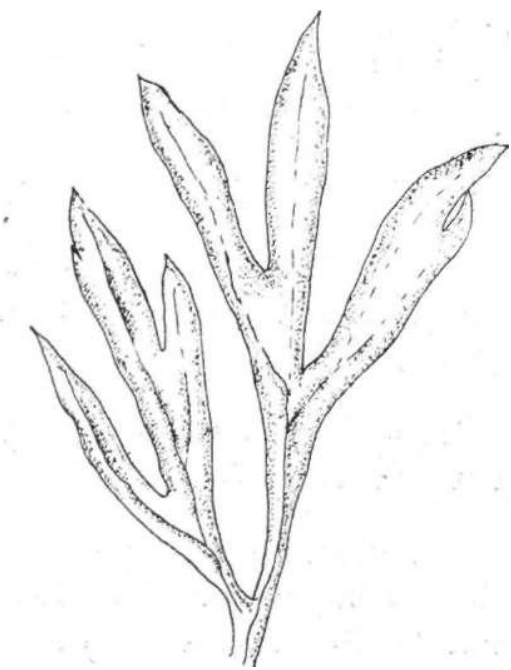

b vaillantii asepala

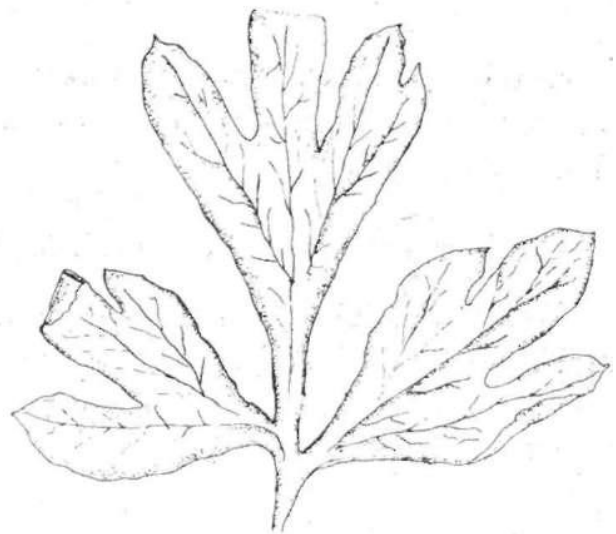

d

gaillardotii

macrocarpa, capreolata judaica

** Verilen şekiller, italik yazılı olan türlere aittir. 
Çiçek durumu:

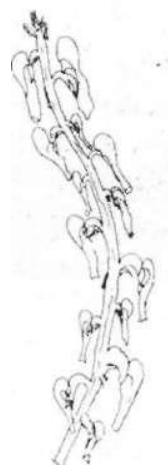

a

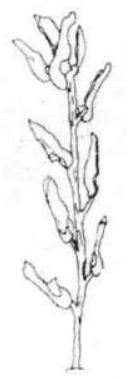

b

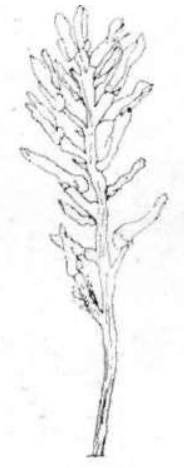

$\mathrm{c}$

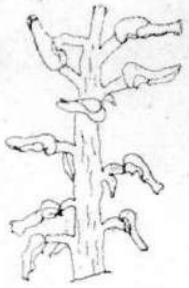

d

kralikii asepala microcarpa judaica macrocarpa officinalis cilicica densiflora parviflora gaillardotii vaillantii capreolata

\section{Brakteler:}

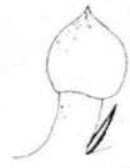

a

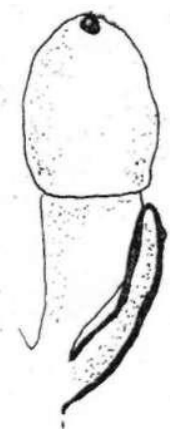

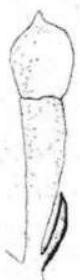

c

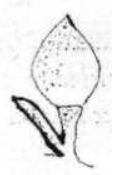

d parviflora asepala gaillardotii jadaica macrocarpa capreolata officinalis cilicica microcarpa vaillantii petteri subsp. thuretii kralikn densiflora 


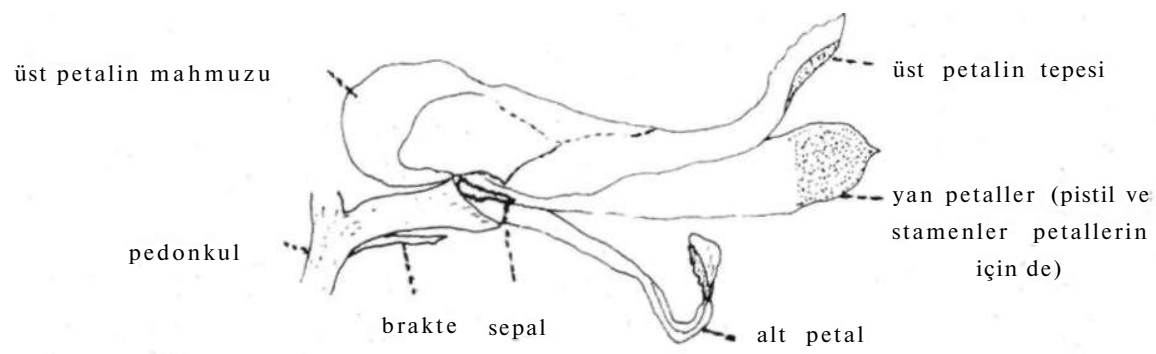

Kaliks

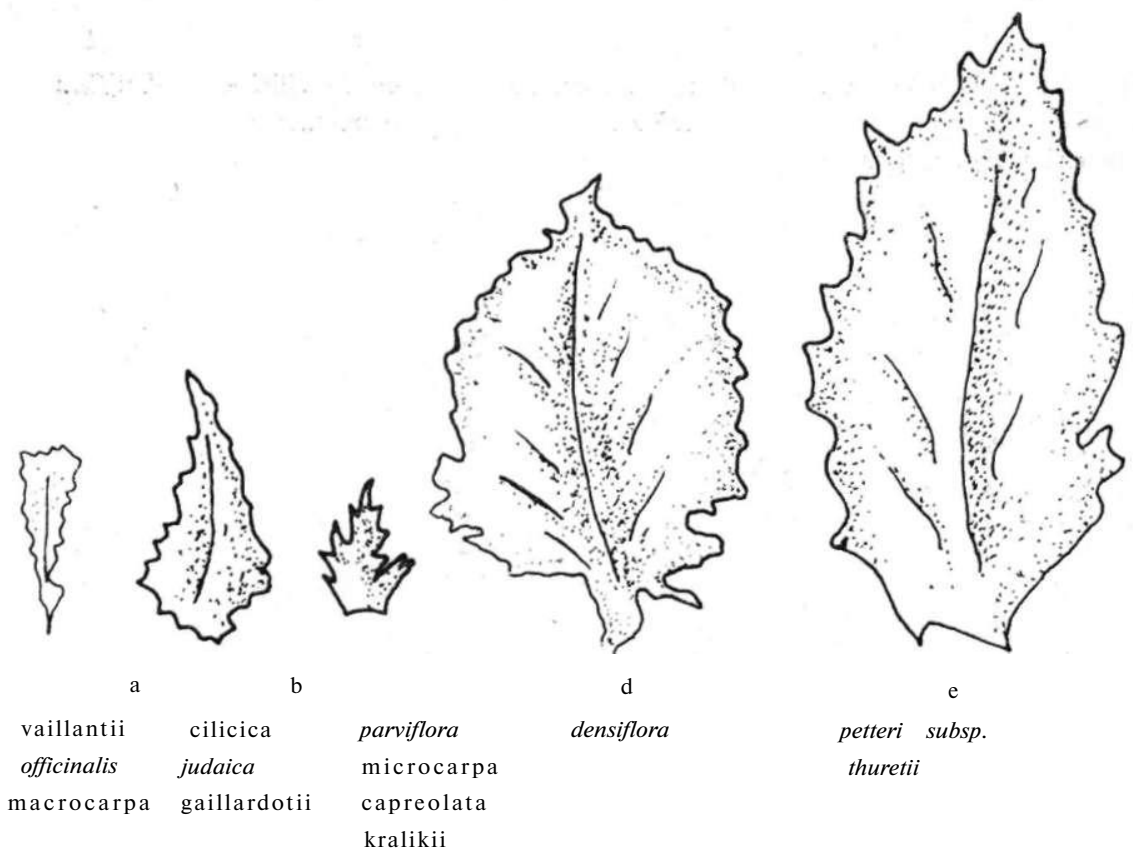

lerin kenarları dişli, şekli lanseolat (a), oblong-lanseolat (b), ovat (c), orbiküler-ovat (d) ya da eliptik (e).

Korolla 4 petalli, koripetal; üstteki petalin tabanı mahmuzlu, mahmuz petale göre az (a) ya da çok genişlemiş (b). 
Korolla:
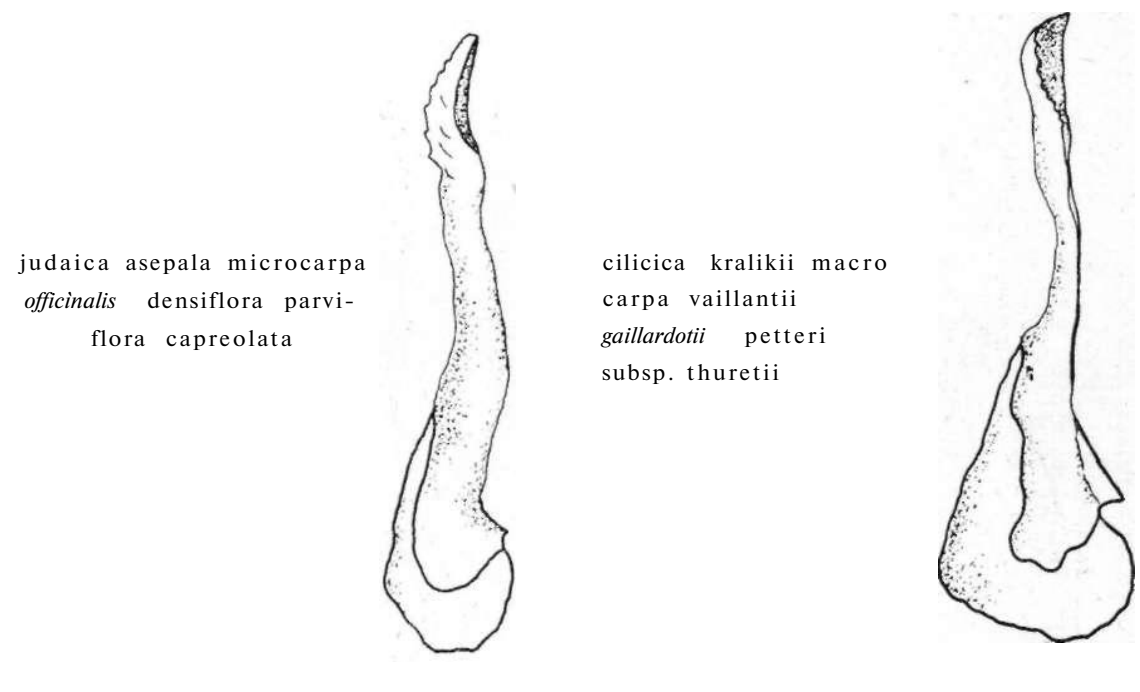

a

Üst petalin tepesi kask, kaskın kenarları düz (a) ya da geriye dönük (b).
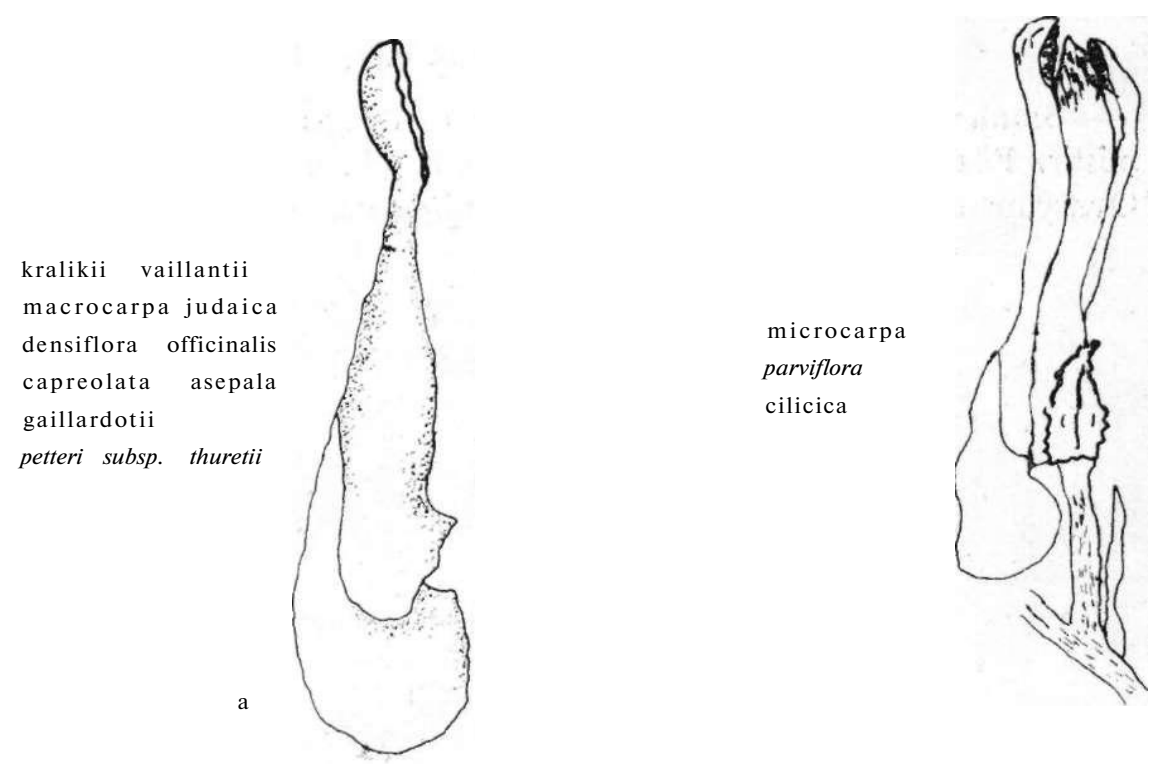
Petallerden ikisi (a) yanlarda bulunur. Altta bulunan petal oblong (b), pandurat (c) ya da spatulat (d) olup, tepede karinalidir.

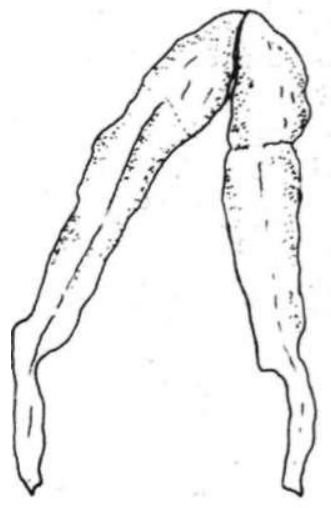

a

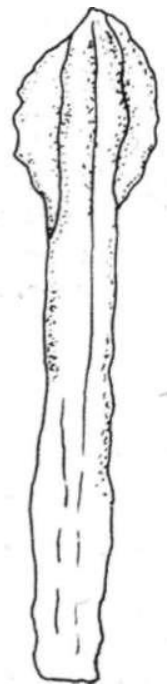

b

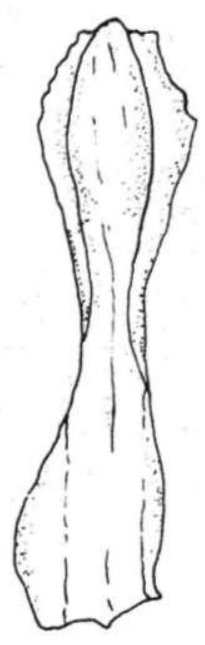

$\mathrm{c}$

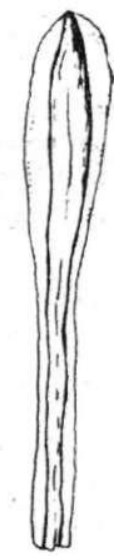

d

$\begin{array}{llc}\text { capreolata gaillardotii } & \text { asepala } & \text { cilicica kralikii } \\ \text { macrocarpa judaica } & \text { officinalis } & \text { parviflora densiflora } \\ \text { petteri subsp. thuretii } & \text { vaillantii } & \text { microcarpa }\end{array}$

Stamenler altı tane, diadelf, üçer üçer iki grup halinde birleşmiştir. Filamentler karakteristik olarak tabanda genişlemiştir (a,b). Ovaryum üst durumlu, stilus uzun ve stigma parçalıdır (c).

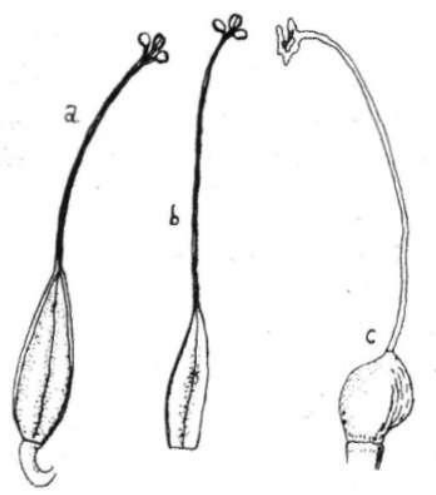


Meyva tek tohum içeren bir nukstur. Bazı türlerde üstten basılmış küre biçiminde, tepesi çukur (a) ya da çıkıntılı (b); bazı türlerde ise küre biçiminde olup tepesi düz (c) ya da apikülat (d) tır.

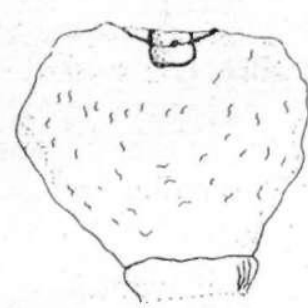

officinalis densiflora

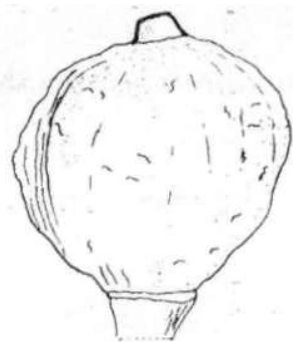

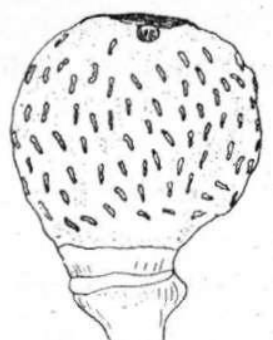

$\mathrm{c}$

cilicica

judaica

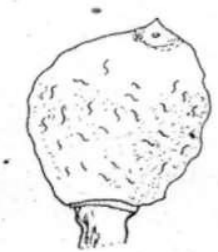

b

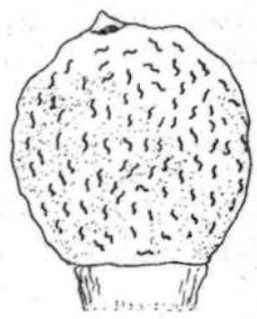

$\mathrm{c}$

microcarpa vaillantii parviflora

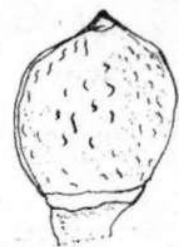

kralikii macrocarpa asepala capreolata vaillantii microcarpa parviflora gaillardotii petteri subsp. thuretii

Meyva kuruduğu zaman yüzeyi pürüzsüzdür (a), az buruşuk (b), buruşuk (c) ya da tuberküllü buruşuk (d) bir görünüm alır.

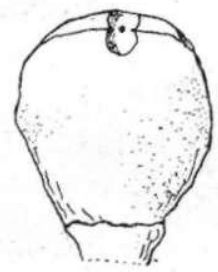
cilicica
capreolata petteri subsp. thuretii

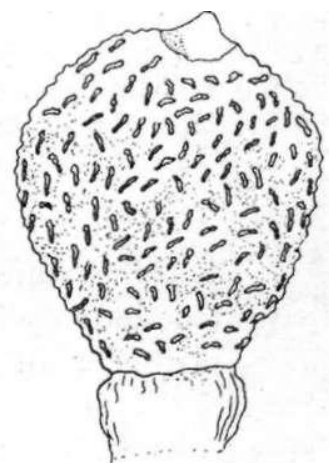

d

judaica densiflora macrocarpa gaillardotii

Yukarıda belirttiğimiz morfolojik özeliklere dayanarak, yurdumuzda varlığ 1 saptanan 13 Fumaria türünü, kolayca birbirinden şu şekilde ayırabiliriz: 
1. Çiçekler 9-14 mm büyüklükte; lamina loblar1 oblong-lanseolat

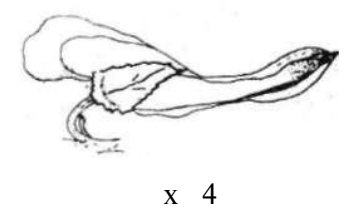

2. Meyvanın tepesi çıkıntılı; mahmuz üst petale göre çok genişlemiş

3. Kaliks korollanın $1 / 4$ ü kadar uzunlukta, sepaller oblonglanseolat

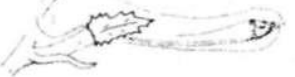

1. gaillardotii

3. Kaliks korollanın $1 / 10$ u kadar uzunlukta, sepaller lanseolat

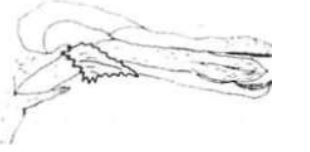

2. macrocarpa

2. Meyvanın tepesi düz; mahmuz üst petale göre az genişlemiş

4. Meyvanın yüzeyi pürüzsüz; pediseller geriye kıvrık

3. capreolata

4. Meyvanın yüzeyi tuberküllü buruşuk, tepesinde belirgin iki siyah leke var; pediseller dik

4. judaica

1. Çiçekler 4-9 mm büyüklükte; lamina lobları linear, linear-lanseolat ya da lanseolat

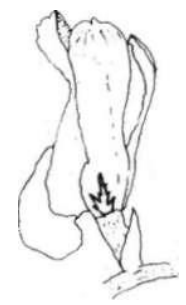


5. Meyva üstten basılmış küre biçiminde

6. Meyvanın tepesi çukur, yüzeyi buruşuk; mahmuz petale göre az genişlemiş, kaskın kenarları düz.

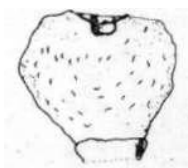

7. Kaliks korollanın $1 / 2$ si kadar uzunlukta, sepaller orbikülerovat;meyvanın yüzeyi tuberküllü buruşuk.

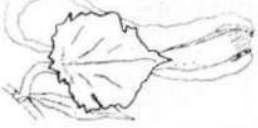

6. densiflora

7. Kaliks korollanın $1 / 4$ ü kadar uzunlukta, sepaller lanseolat; meyvanın yüzeyi az buruşuk

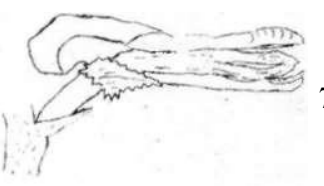

7. officinalis

6. Meyvanın tepesi çıkıntılı, yüzeyi pürüzsüz; mahmuz petale göre çok genişlemiş, kaskın kenarları geriye dönük

5. cilicica

5. Meyva küre biçiminde, tepesi apikülat

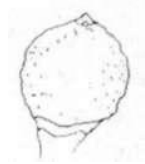

8. Pediseller geriye kıvrık; meyvanın yüzeyi belirsiz buruşuk

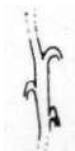


9. Kaliks korollanın 1/2 si kadar uzunlukta, sepaller eliptik;

brakte pediselden kisa, linear-lanseolat
8. petteri subsp. thuretii

9. Kaliks korollanın $1 / 3$ ü kadar uzunlukta, sepallar ovat;

brakte pediselden

uzun, linear-oblong.
9. kralikii

8. Pediseller dik; meyvanın yüzeyi belirgin buruşuk.

10. Brakte pedisele eşit uzunlukta, linear

11. Sepal var, kaskın kenarlar1 geriye dönük

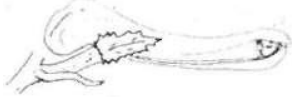

10. parviflora

11. Sepal yok, kaskın kenarları düz.

13. asepala 
10. Brakte pediselden kisa, linear-lanseolat

12. Sepaller lanseolat; alt petal pandurat; kaskın kenarları düz.

12. vaillantii

12. Sepaller ovat; alt petal spatulat; kaskın kenarları geriye dönük.

11. microcarpa

Bu çalışmada, Papaveraceae familyasının Fumarioideae alt familyasına ait bir genus olan Fumaria L. cinsinin, memleketimizde yetişen 13 türünün morfolojik özellikleri tayin edilmiştir. Saptanan yeni karakterlerin de ilâve edilmesiyle, türlerin ayırımlarında yararlanılacak bir tayin anahtarı hazırlanmıştır.

\section{S U M MARY}

In this study, morhological characters of Fumaria L. species growing in Turkey have been determined. Fumaria L. is a genus belonging to the subfamily of Fumarioideae in Papaveraceae family) The genus Fumaria is represented by 13 species in Turkey. During the botanical investigation, some new characters are obtained. By addition of these new characters, a determination key by which species are easily distinguished has been prepared.

\section{T E Ş E K K Ü R}

Morfolojik özeliklerin bu biçimde düzenlenmesi fikrini veren, sayın hocam Prof. Dr. Nevin Tanker'e bir kez daha teşekkür ederim. 


\section{I T E R A T Ü R}

1- Pugsley, H.W.: J. Linn. Soc. Bot. 47, 427-69 (1927).

2- Pugsley, H.W., Ibid. 50, 541-59 (1937-)-

3- Davis, P.H.: Flora of Türkey and the East Aegean Islands Vol. 1, 242, University Press, Edinburg (1965).

4- Boissier, E., Flora Orientalis, Supplementum, 26 Genevae et Basilieae (1888).

5- Post, G.E., Dinsmore, J.E., Flora of Syria, Palestine and Sinai Vol. 1, 43, American Press, Beirut (1932).

6- Goste, H., Flahault. C.H., Flore de la France, Tome I, 67, Librairie Des Sciences Et Des Arts, Paris (1937).

7- Hegi, G.: Illustrierte Flora Von Mittel-Europa, Band IV, 1. Teil, 66, Carl Hanser Verlag, München (1958).

8- Tutin, T.G., Heywood, V.H., Flora Europaea Vol. 1,255, University Press. Cambridge (1964).

9- Bardeau, F., La Pharmacie du Bon Dieu, Éditions Stock, Paris (1973).

10 - Garnier, G., Bézanger-Beauquesne L., Debraux, G.: Ressources Médicinales de la Flore Française, Tome 1, Vigot Freres Editeures, Paris (1961).

11- Golse, J., Précis de Matière Médicale Place de l'Odèon, Paris (1955).

12- Decaux, F., Formulaire de Phytothérapie, Amédée Legrand et Cie Editeurs, Paris (1956).

13 - Reynier, M., Lagrange, E., Godard, F., Forgacs, P., Pesson, M., Roquet, F., Trav. Soc. Pharm. (Montpellier) 37 (2), 85-102 (1977).

14- Perrot, E., Paris, R.: Les Plantes Médicinales, 1, Presses Universitaires de France, Vendome (1971).

15- Hoppe, H.A.: Drogenkunde, Band 1, 8. Auflage, Walter de Gruyter, Berlin (1975).

16- Susplugas, J., Massa, V., Susplugas, P., Touchot, M., Trav. Soc. Pharm. (Montpellier) $34 \quad(2), \quad 109-13 \quad$ (1974).

17- Massa, V., Sasplugas, P., Aneli, A.: İbid. 31 (3), 233-6 (1971).

18 - Mirzabaeva, M., Umarov, A.U., Shukurova, M.R., Khim. Prirodn. Soedin. 7 (6), 826-7 (1971).

19- Pandey, V.B., Dasgupta, B., Ghosal, B.: J. Indian. Chem. Soc. 50 (3), $230-1$ (1973). 